\title{
Essay: Adorno on the Form of Philosophical Writing
}

\author{
Feng $\operatorname{TaO}^{1^{*}}$ \\ ${ }^{1}$ College of Philosophy, Nankai University, Tianjin,300371 6, China \\ "Corresponding author. Email: taofeng@mail.nankai.edu.cn
}

\begin{abstract}
Adorno inherits Lukács and Benjamin's thoughts on philosophical writing form and believes that essay is a new form of philosophical writing and a linguistic medium of art and philosophy. Adorno criticizes traditional writing form of philosophy on the basis of criticizing the philosophical identity. Therefore, he criticizes several problems of the traditional writing style, such as the presupposing theme, the ossification, the systematization, for criticizing the philosophy and language of identification. He suggests that we must firstly reform it in terms of language and writing form if we want to reform the philosophy of identification. Adorno believes that the form of essay without presupposition and non-systematism can avoid the problem of identification. Therefore, he regards essay as the combination of art and philosophy, and art criticism as the way to present the truth content.
\end{abstract}

Keywords: essay, Adorno, philosophical writing, identification

\section{INTRODUCTION}

Since the 20th century, western literature and philosophy have respectively reflected and innovated their own writing forms. In the field of western philosophy, influenced by multiple thoughts such as linguistic turn, Marxist theory and critical theory, some philosophers began to think about the problems of philosophical writing and the possibility of innovation. One of the most representative philosophers is T.W.Adorno, the representative of Frankfurt school. He inherited Lukács and Benjamin's thoughts on criticizing the form of writing. He claims that essay is a new form of philosophical style and a linguistic medium of art and philosophy.

\section{LUKACS AND BENJAMIN ON THE ESSAY}

Essay, as a short art criticism, is a common writing genre, but it was not until Lukács that it was endowed with an important position. Lukács discussed the form of essay in detail in "On the Nature and Form of the essay". In this article, he first raised the question whether a unified literary form in the modern world is still possible. He thought that with the separation of science and art, the world and people cannot be kept complete. Science provides us with facts and the connection between facts through content, while art provides us with soul and destiny through form. The separation of the science and art causes the incompleteness of human soul and life. The life feels it is limited by the form and therefore not free, and the form will claim that the life is disordered and chaos. As the medium of philosophy, the essay unifies the form and the life.

Then Lukács asked: is the critique, the essay, as a work of art, a genre? Is the essay an art or a science? He inspected the development history of essay, and gave some excellent examples of essay, such as Plato's dialogue, Montagne's essay, and Kierkegaard's imaginative diaries and stories. Finally, he thought that, on the one hand, essay has a scientific side, it is a kind of judgment, but it is not a "verdict" but just a process of judgment; on the other hand, essay is also an art form, an autonomic and a complete "giving-of-form" to an autonomous and complete life [1]. This form of essay has become a kind of literature form with redeeming significance in the modern world. This is because essay itself has fragmentation, which is a resistance to the totalization of society and against the establishment of an all-encompassing system in the traditional western philosophy.

Benjamin also attached great importance to the function of essay. He regarded the function of art criticism provided by essay as an important way to find Truth Content. He took the different functions of essay and systematic philosophical discourse as the starting point. Benjamin examined the characteristics of philosophical writing and thought that philosophical writing must constantly face the problem of representation. He distinguishes between "discourse" and "essay", and analyzed the limitations of the traditional philosophical discourse. In his opinion, the only intention of the treatise is to be authoritative. It regards truth as its object of knowledge, which is a kind of "didactic admonition". It is impossible to really grasp the truth through a form of treatise. Benjamin believed that essay could grasp Truth Content in the "most minute details", he emphasized the grasp of fragmentary, rather than epic art, and emphasized the fracture rather than the continuity of essay. Essay is the only style suitable for philosophy research, and idea is the object of this kind of research[2]. 


\section{ADORNO ON ESSAY}

\section{1 the Form of Essay}

Adorno obviously inherited this kind of anti-systematic way of writing. Adorno's emphasis on essay is more from the perspective of its language reformation. Adorno hopes to reconstruct the reified language and replace it with a mimeticexpressive language, which can only be realized in the form of essay, because the essay itself is an anti-system fragment, and as an art criticism, it is the intermediary between art and Philosophy.

Adorno discussed the form and language of essay in "The Essay as Form", and further developed Lukács and Benjamin's thoughts on essay. He first criticized Lukács treating essay as an art form. Adorno claims that essay "is distinguished from art by its medium, concepts, and by its claim to a truth devoid of aesthetic semblance."[3] The key difference between essay and art is that essay needs concept, and does not have certain aesthetic appearance like art. The biggest characteristic of art language is that it is the language and knowledge without concept, which makes it difficult for art to convey, compare and measure by itself. It needs to be interpreted and grasped by the concept. This kind of concept that can interpret art is not the reified concept, but the concept that has been reconstructed in essay. Adorno calls the relationship between essay and concept "appropriate", which is compared to a method of learning a foreign language. People connect concept and object in specific context and real environment, and constantly correct it through practical experience. People will use "fantasy" to try and adjust constantly, and finally find a more appropriate description. This kind of fantasy belongs to the subject impulse of the essay subject. However, the fantasy is that the subject constantly imagines the possible way to reach the object under the condition of following the object. Therefore, the subject's fantasy is limited by the object law. This fantasy "is castigated in the name of objective discipline", Adorno said[4].

However, there are obvious similarities between essay and art. Firstly, essay is also autonomic just like art. That is to say, the interpretation criteria of essay are internal, derived from its own logic, rather than external force[5]. Adorno is against setting criteria in advance or taking the subject impulse of the interpreter as the criteria. The criteria of essay come from the object itself, and there is no fixed criteria system in essay itself. It does not have the so-called first principle, nor will it develop a certain principle. Adorno opposes the fixation and systematization of essay. Therefore, it is not as complete and systematized as the traditional philosophical treatise. Secondly, the object of interpretation and reflection of essay is artwork. Essay is to show the truth content of art for people, so it is the intermediary of art. Thirdly, the language of essay is a kind of non-reified language and an aesthetic language. Because the traditional inference logic is based on a wrong logic, it is impossible to reach the truth. Essay's contempt for inferential logic, its strong interest in association and semantic equivocation, makes it closer to the aesthetic language. Adorno concluded that essay has the possibility of non-concept things but will not become art. This means that "rightness" is more important than the rules of inference logic[6]. These rhetorical devices, such as association and semantic equivocation, are just for the purpose of realizing the anti-reification of language, not for some artistic technique, such as poetic language.

Adorno believes that essay is not an art form, but he does not regard it as a form of science. Science and traditional philosophy are systematic and governed by some external principles. They use inferential language. Because of its short form and relatively free style and language style, essay can oppose some systematic language and discourse. Adorno believes that essay does not follow the traditional rules of organized science and theory which the order of things is identical to the order of ideas. However, since ideas can no longer really understand things because of reification, how can these two kinds of orders be identical? Therefore, Adorno said, "Because the unbroken order of concepts is not equivalent to what exists, the essay does not aim at a closed deductive or inductive structure."[7] However, essay is closely related to Philosophical and scientific treatise, because they all need to use concepts and reflect and are all the search for truth. What's different is that essay pays more attention to the use of language or rhetoric, rather than a logical argument based on identity. For Adorno, essay is the most outstanding form of criticism because it is impure and relies on rhetoric rather than logic.[8]

\subsection{The Language of Essay}

Adorno's emphasis on rhetoric has been shown as early as in Negative Dialectics. He emphasizes the relationship between philosophy and language, and believes that language is actually the intermediary and vehicle of philosophy. Positivism and Analytic philosophy try to amend and rebuild the language of philosophy. Adorno believes that this will actually deconstruct philosophy fundamentally. In fact, philosophy expresses the things that can't be expressed through language. The medium between philosophy and its objects is language. Of course, this kind of language is not a reified language, but a dialectic, a negative dialectic. Adorno believes that this dialectics can eliminate the obstacles between the reified language and the object, so that the subject can recognize the object directly. Essay is the application of this kind of rhetoric. It restores the expressive function of language, reunifies the divided image and symbol, and finally realizes the unity of science and art[9].

Adorno thinks that essay language should have both the function of expression and the function of communication. Communicative language should not be denied only because it has been reified. It still has the function of delivering information. Adorno also thinks that language can't be completely expressive. The functions of expression and communication of language have been intertwined[10]. We should try to recover the lost expression elements in language. The communicative function of essay language is also essential, because it is also to interpret the truth content of art, and make this interpretation become communicable. In 
Adorno's opinion, essay is an important experimental field for the transformation of traditional language. In essay, the separation state of language can be changed[11].

\subsection{The Task of Essay}

The ultimate purpose and task of essay is to grasp and explain the truth content in art. Because of the particularity of its form and language, it can undertake this task. Essay is art criticism and a direct reflection on artworks. Essay grasps works of art which are objects in epistemology through language because essay language is a language with both expression and communication functions. Therefore, essay can not only grasp artworks, but also disclose truth in works of art. Essay does not presuppose any original assumption, which makes it not fall into a certain ossified and fixed form. What essay attaches importance to is the concrete content. This content does not refer to the textual research of the artist's life or intention, but rather to restore the artwork to history and follow the internal logic of the artwork to think[12]. Essay seeks truth content in its object, its internal historical object. Because of its fragmentariness, essay can give up some illusion of eternity and system. The Truth Content shines out in the fragments of art and essay can constantly approach it. Through the deconstruction and reorganization of language, essay does not try to extract some eternal things from such fragments but to return eternity to the moment. At this point, Adorno and Benjamin are consistent. Benjamin emphasizes the discontinuity and fracture of history, and believes that people can be redeemed in the moment when the truth shines. Thus both of them put the opportunity of redemption into the reflection and interpretation of art, that is, essay. Adorno stresses that essay does not instrumentalize its own language and encourages to make the object clear through linguistic differences. The essay form is broken and has cracks. Essay achieves its unity by recognizing these cracks, rather than covering it.

In essay, language is expressive and communicative. This kind of language is neither pure symbol and concept, nor a kind of intuitive without concept. "The balancing act of Adorno's essays consists in the careful avoidance of a strictly scientific as well as an exclusively aesthetic or intuitive method." [13]

The language of essay must be distinguished from that of artistic works. For example, the language of poetry is the art itself. It can ignore the communication of language and try to break all traditional languages. Adorno believes that through a special form of "parataxis", the language of poetry can break the traditional syntactic structure and deliberately disturb the logical hierarchy in sentence construction (syntax), that is, the form of judgment and proposition. Just like logic of decomposition, Juxtaposition is thus regarded as a negation of the integrated principle of spirit itself. It is actually a form, but this form is not from the external rules, but the result of the development of poetry language itself[14]. Through selfliberation of the form, poetic language to a certain extent smashes the shell of reified language, but it also makes language difficult to communicate at the same time. In poetry, language should be more specific and personal. Poetry should preserve individual moments, which have not yet been attributed to the concepts. Only by paying attention to the particular can poetry reach the universal.

Essay must seek an unstable balance between conceptual and poetic language. Although essay is also against some deduction and induction, it needs to unify the individual and the general with the help of concept, so as to realize the unity of expression and communication and the universal communication of truth content.

\section{SUMMARY}

From this, it can be seen that Adorno criticizes the writing style of the traditional philosophy from the angle of criticizing the philosophy of identification. Therefore, he criticizes several problems of the writing style, such as preset theme, fixation, systematization, etc., all for criticizing the philosophy of identity and its language. Adorno believes that a kind of essay form without presupposition and nonsystematization can avoid identification. Therefore, he regards essay as the combination of art and philosophy, and art criticism as the way to present the Truth Content.

However, while Adorno was criticizing the philosophical style, he not only revealed its shortcomings, but also abandoned the advantages of the original style, such as logic and clarity. As Adorno said in Negative Dialectics, philosophy cannot be fully expressed, but urge to express[15]. Any form of philosophical writing style has its advantages and disadvantages. The essay advocated by Adorno also has its ambiguity, lack of logic and obscure.

In my opinion, philosophical styles should be more diversified. For example, traditional forms of dialogue and poetry can be used as philosophical writing forms. The traditional philosophy treatise should also keep its advantages and absorb the advantages of other styles. Adorno's own works are mostly written in essay style advocated by him, which has also become his style.

Philosophical writing style is not as concerned as literary style (form). The key is that philosophical expression is often simplified as a tool, and the content and form of expression are separated. The discourse of Adorno inspiring us may not lie in his essay style, but in whether philosophers should pay attention to the unity of means and content of expression, to the role of forms of expression when they think and express philosophical problems.

\section{ACKNOWLEDGMENT}

This paper is supported by the National Social Science Fund of China and the name of this project is "The Language Thought in Adorno's Philosophy" under grant No. 16BZX118. 
[8]Hohendal P.U., Prismatic Thought: Theodor W. Adorno. University of Nebraska Press. 1995.p.117

[1] Lukacs G., Soul and Form. trans. Anna Bostock. Cambrige: the MIT Press.1974. p.18

[2] Benjamin W., The Origin of German Tragic Drama, trans. J.Osborne,London:Verso,1998. pp.27-29

[3][4][5][7][12]Adorno T.W., Notes To Literature,Volume 1. ed. Rolf Tiedemann. trans. Shierry Weber Nicholsen. Columbia University Press,1992 (Adorno, 1992a ) . p.5, p.4, p.4-5, p.10, p.11

[6]Hohendal P.U., "Adorno: The Discourse of Philosophy and the problem Of Language" //The Actuality of Adorno: Critical Essays on Adorno and the Postmodern[C]. ed Max Pensky. State University of New York Press. 1997.p.75
[9] [13] Plass U., Language And History In Theodor W. Adorno's Notes To Literature. Routledge New York \&London. 2007.p.8, p.8

[10]Adorno T.W., Hegel: Three Studies. trans Shierry Weber Nicholsen. The MIT Press.1993.p.105

[11]Foster R., Adorno: The Recovery Of Experience. State University of New York Press.2007.p.17

[14]Helmling S., Adorno's Poetics of Critique. Continuum International Publishing Group.2009.p.114

[15]Adorno T.W., Negative Dialectics, trans. E.B.Ashton,Taylor \& Francis e-Library, 2004.p.10 